\title{
El "común” y su "vana filosofía”. Formación de sistemas de conocimiento alternos en el virreinato de la Nueva Granada
}

Resumen: El devenir científico en la América colonial se ha estudiado generalmente a partir de los contenidos de la ciencia moderna que fluyeron desde Europa hacia las posesiones ultramarinas, por lo que se ha omitido que entre los pueblos amerindios, africanos, mestizos y todas sus "castas" intermedias también hubo espacio para la creación intelectual. Este artículo allana el camino para encontrar algunas pistas sobre la existencia de aquellas matrices de pensamiento diferenciales, así como de los protocolos, conceptos, productos y sus artífices que permitieron desarrollar alternativas de bienestar propias y puntos divergentes al orden de dominación instaurado por el régimen colonial durante el siglo XVIII. Palabras clave: sistemas de conocimiento, saberes alternos, circulación cultural, eurocentrismo, colonialismo.

\section{The "common" and its "vain philosophy". Formation of alternative knowledge systems in viceroyalty of New Granada}

Abstract: The scientific developments in colonial America have been generally studied from the viewpoint of the modern science that flowed from Europe to the overseas possessions. For this reason, it has been overlooked that among the Amerindian, African, mestizo peoples and all their "intermediate castes" there was also room for intellectual creation. This article paves the way to find some clues about the existence of differential ways of thought, as well as protocols, concepts, products and their architects. These allowed for the development of welfare alternatives and points of view that were divergent from the order of domination established by the colonial regime during the 18th century.

Keywords: knowledge systems, alternative knowledge, cultural circulation, eurocentrism, colonialism.

\section{0 "comum" e sua "filosofia vã". Formação de sistemas alternativos de conhecimento no vice-reino de Nova Granada}

Resumo: A evolução científica na América colonial tem sido estudada em geral a partir dos conteúdos da ciência moderna que fluíram da Europa até as possessões ultramarinas, pelo que tendeu a ser esquecido que, entre os povos ameríndios, africanos, mestiços e todas as suas "castas" intermediárias também houve espaço para a criação intelectual. Este artigo abre o caminho para encontrar algumas pistas sobre a existência dessas matrizes de pensamento diferencial, bem como dos protocolos, conceitos, produtos e seus artífices, que permitiram desenvolver alternativas de bem-estar próprias e pontos divergentes à ordem de dominação estabelecida pelo regime colonial durante o século XVIII.

Palavras-chave: sistemas de conhecimento, saberes alternativos, circulação cultural, eurocentrismo, colonialismo.

Cómo citar este artículo: Jaime Andrés Peralta Agudelo, “El 'común' y su 'vana filosofía'. Formación de sistemas de conocimiento alternos en el virreinato de la Nueva Granada”, Trashumante. Revista Americana de Historia Socia/16 [2020]: 148-169. DOI: 10.17533/udea.trahs.n16a08

Fecha de recepción: 26 de junio de 2019

Fecha de aprobación: 2 de abril de 2020

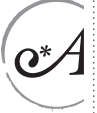

Jaime Andrés Peralta Agudelo: Doctor en Historia por la Universidad Pablo de Olavide. Actualmente es profesor de la Universidad de Antioquia.

Correo electrónico: jaime.peralta@udea.edu.co 


\section{El "común" y su "vana filosofía”. Formación de sistemas de conocimiento alternos en el virreinato de la Nueva Granada*}

Jaime Andrés Peralta Agudelo

\section{Introducción}

Cuando a finales de mayo de 1740 don Miguel de Santisteban recorrió Ualgunas secciones de la costa del Pacífico del virreinato de Nueva Granada, se sorprendió con el conocimiento botánico y con el manejo de alternativas médicas, alimenticias y artesanales que los pobladores daban a las diversas especies de fauna y flora de la región. De su propia boca conoció, por ejemplo, que los esclavos y libres adscritos al puerto y astillero de Guayaquil eran expertos en el reconocimiento, clasificación y utilización de las mejores especies maderables para la actividad naviera y, al dar cuenta de estos conocimientos locales, anotó en su diario personal que sus "simples" interlocutores no dudaban en ponderar

la abundancia, diferencia, calidad y propiedades de las maderas que había en las dilatadas selvas del territorio de la ciudad y su provincia sobre todas las del universo. Unos las numeraban por sus nombres que pasaban de 30, todas preciosas, prefiriendo la de Guachapeli por la docilidad de dejarse labrar su grueso y condición casi incorruptible para la armazón interior de un navío [...] Otros eran del parecer que el mangle era más a propósito para la quilla [...] por su solidez y fuerte contextura [...] Ponderaban algunos [otros] la calidad del roble de aquellos montes para los tablados y los Palos de María para arboladuras, dando ventajas a estos sobre los pinos de Noruega. ${ }^{1}$

* Este artículo hizo parte del proyecto de investigación "Las travesías de los saberes entre Europa, África y América del siglo XVII al XX. Un caso de historias interconectadas en Colombia”. Fue financiado por la Facultad de Comunicaciones de la Universidad de Antioquia y la Escuela de Ciencias y Humanidades de la Universidad Eafit.

1. Miguel de Santisteban, Mil leguas por América. De Lima a Caracas, 1740-1741. Diario de don Miguel de Santisteban (Bogotá: Banco de la República, 1992) 95. 
Como Miguel de Santisteban, otros tantos encontraron (así fuera a su pesar) que en todos aquellos rincones — percibidos a priori como "vacíos de razón" y poblados de grupos humanos con "mentes débiles", proclives tan solo a las "vanas ideas" y a las "groseras especulaciones" - existían sólidos cuerpos de conocimiento alternativos que brindaban a sus portadores certeras explicaciones sobre el medio natural y social donde estaban insertas sus comunidades. De esto se percataron otros funcionarios, viajeros, comerciantes, letrados, señores de tierras y de hombres, misioneros y, por supuesto, académicos formados en los nuevos protocolos del saber provenientes de la ciencia ilustrada, los cuales se estaban irradiando desde Europa hacia otros confines del planeta.

Es más, en sus estudios se valieron de muchos de sus hallazgos, aunque los enmascararon dentro de los protocolos de enunciación de la ciencia europea de aquellos tiempos. Sin embargo, la mayoría de las pocas notas que redactaron sobre los diversos saberes de la "multitud" neogranadina del siglo XVIII y comienzos de la siguiente centuria mostraron que aquella evidencia de pluralidad del fenómeno del saber fue paradójicamente subvalorada y presentada muchas veces desprovista de historia, de contexto social y de protagonistas directos y, por ende, rotulada en la mayoría de las ocasiones como fruto espontáneo de "afortunadas casualidades" o de la imperiosa necesidad de la sobrevivencia diaria. Es así como para hablar de sistemas de conocimiento estructurados solo se podía tomar como eje de validación a la tradición ilustrada proveniente del "orbe civilizado", y esa diferenciación dicotómica intencionadamente construida sobre el universo del saber resultó funcional para los fines de dominación de geografias y sociedades diferentes en las que estaban empeñados los poderes metropolitanos y sus agentes situados en las posesiones coloniales. ${ }^{2}$

Aquel postulado mutuamente excluyente planteaba una radical distancia entre lo representado como "conocimiento útil" (lo legítimo) y las "vanas filosofias" (lo ilegítimo). Por lo tanto, a los portadores del primer orden les correspondía el derecho no solo de incorporar los saberes ajenos dentro de su propio marco de elucidación científica para darles patente de ingreso al genuino acervo del saber humano, ${ }^{3}$ sino erradicar varias de aquellas "falsas suposiciones" y "pensamientos desordenados" para implantar en sus gestores originales las "luces de la razón" que ellos como adalides civilizatorios estaban trayendo al ámbito americano. Como indica Mauricio Nieto Olarte sobre este afán de diferenciación dicotómico:

2. Véase Andrea Cadelo Buitrago, "Hábito e ideología criolla en el Semanario del Nuevo Reino de Granada", Pensar el siglo XIX. Cultura, biopolítica y modernidad en Colombia, ed. Santiago Castro-Gómez (Pittsburgh: Biblioteca de América / Instituto Internacional de Literatura Iberoamericana, 2004) 5-52.

3. Para conocer varias de las estrategias de apropiación y de presentación de saberes ajenos al mundo académico ilustrado europeo dentro del contexto neogranadino, véase Jaime Andrés Peralta Agudelo, "De 'delirios ignorantes' a 'cultas reflexiones': la Ilustración europea y la apropiación de los saberes de la periferia colonial", Fronteras de la Historia. Revista de Historia Colonial Latinoamericana 19.1 (2014): 72-97. 
el reconocimiento a la experiencia de los salvajes, la cual sin embargo debe diferenciarse de la observación disciplinada, del "experimento" y del conocimiento; es más bien fruto de la necesidad y del accidente que de una observación ordenada [...] Una condición básica y necesaria para hacer ciencia es estar familiarizado con las convenciones y con los sistemas de clasificación aceptados dentro de la historia natural en Francia y Europa. Para reconocerse como 'ilustrados' es necesaria la continua afirmación de la diferencia, de la distancia existente entre sus conocimientos y cualquier forma de saber popular. ${ }^{4}$

Para comenzar a recorrer una vía distinta de aproximación a los sistemas alternos de conocimiento del "común", el presente artículo se abocará a encontrar no solo algunas pistas sobre su existencia (dejadas paradójicamente por aquellos que tanto se esforzaron en ocultarlas), sino algunos de los protocolos de indagación de la realidad utilizados, de los conceptos elaborados, de los procesos de experimentación implementados, de los productos desarrollados, amén de los artífices que los crearon y que dieron vida a lo que desde la óptica de las élites del momento era tan solo la "ciencia de los rústicos", 5 por no decir la de los "salvajes" y aun la de los "bárbaros". 6

\section{Sistemas de conocimiento alternos}

Al considerar la diversidad de sociedades y la fragmentación de la información inscrita en las fuentes coloniales, se hace evidente en primer lugar que las matrices epistemológicas de cada sistema de conocimiento especializado sobre la naturaleza y el hombre estaban íntimamente imbricadas dentro del devenir histórico, la experiencia cultural y el entramado de relaciones que cada comunidad había hilvanado a través del tiempo. A diferencia de la ciencia moderna, se trataba de saberes colectivamente producidos y socialmente apropiados. Así, por ejemplo, la estructura cognoscitiva del saber médico de los indígenas cuna (hoy gunadule o tule) —ubicados en el extremo noroccidental del virreinato de Nueva Granada - tenía un anclaje sustancial dentro del universo de creencias que componía su cosmogonía ancestral.

4. Mauricio Nieto Olarte, Orden natural y orden social. Ciencia y política en el Semanario del Nuevo Reyno de Granada (Bogotá: Universidad de los Andes, 2008) 278-279.

5. Cuando se habla de la observación, experimentación, codificación, utilización y transmisión de saberes se hace en el sentido más general del término, es decir, de procesos mentales que son relativamente afines dentro del conocimiento humano, así su génesis, contenidos, función y utilidad sean productos históricamente diferenciados como se ve en este texto.

6. Algunos autores han analizado los términos de esta pugna por la primacía intelectual, véase Mary Louise Pratt, Ojos imperiales. Literatura de viajes y transculturación (Bernal: Universidad Nacional de Quilmes, 1997); Enrique Dussel, "Europa, modernidad y eurocentrismo", La colonialidad del saber: eurocentrismo y ciencias sociales. Perspectivas latinoamericanas, comp. Edgardo Lander (Buenos Aires: Consejo Latinoamericano de Ciencias Sociales, 2000); Mauricio Nieto y otros, “"El influjo del clima sobre los seres organizados' y la retórica ilustrada en el Semanario del Nuevo Reyno de Granada", Historia Crítica 30 (2005): 91-114. 
Es así como conocían y sabían predecir distintos fenómenos naturales (tormentas, rayos, lluvias, ciclos solares y lunares, evoluciones de cuerpos celestes, etcétera). Estos fenómenos eran percibidos como agentes transmisores de mensajes de insatisfacción o beneplácito de sus diversas entidades espirituales —en especial del dios creador Páptumat o "Gran Padre"-, y se basaban en los comportamientos cotidianos que la colectividad hubiese hecho, ya fuera para mantener o para transgredir el orden primigenio por ellas trazado. Los eventos de castigo se expresaban entonces a través de varias calamidades, y entre ellas figuraban, por supuesto, las enfermedades.

La etiología de los desastres era percibida como de origen sobrenatural. ${ }^{7}$ De esta manera se consideraban las causas de cada afectación a la salud individual o colectiva, las muertes debidas a traumas accidentales, las hambrunas gestadas por la pérdida de cosechas o de piezas de caza y hasta la destrucción de poblados enteros debido a inundaciones o huracanes, o a acciones violentas como la invasión de los españoles o de grupos cimarrones negros o de sus enemigos chocoes, entre otros eventos calamitosos. De allí que la comunidad entera estuviera atenta a los significados subyacentes tras los acontecimientos generados en el entorno natural circundante.

De uno de ellos fue testigo directo el jesuita Jacobo Walburger en la misión de Chucunaque en febrero de 1747, periodo en el cual se hizo visible un eclipse de Luna. Este fenómeno astronómico causó tal conmoción en los indígenas que "las mujeres comenzaron a llorar a gritos quexandose que su Dios, o estaba enfermo, o sumamente enfadado, ya no, decian, hay otro remedio sino morirse todos de hambre". ${ }^{8}$ Presas del pánico, solicitaron la intervención directa de los "leres" o chamanes para conocer con certeza el mensaje que desde el entorno metafisico se les estaba enviando por intermedio de aquel misterio cósmico.

Ellos "empezaron en sus casas a lerear, para que el Diablo les revelase, lo que significaba este eclipse”. El ceremonial de canto y oración duró hasta el amanecer, cuando por fin se les transmitió el significado de la manifestación astronómica observada. "A una voz consintieron" en que el "Diablo" (según la óptica del sacerdote) les había revelado que uno de los caciques principales de la comunidad

7. Para conocer más aspectos del universo cultural cuna a finales de la colonia, véase Jaime Andrés Peralta Agudelo, "Los cuna y sus saberes médicos. La 'ciencia' de los 'bárbaros' bajo la mirada del mundo ilustrado", Historia Crítica 46 (2012): 44-65; Carl Henrik Langebaek, "Introducción”, El diablo vestido de negro y los cuna del Darién en el siglo XVIII. Jacobo Walburger y su Breve noticia de la Provincia del Darién, de la ley y costumbres de los Yndios, de la poca esperanza de plantar nuestra fé, y del número de sus naturales, 1748, ed. Carl Henrik Langebaek (Bogotá: Universidad de los Andes / Banco Popular, Fondo de Promoción de la Cultura, 2006) 2-64.

8. Jacobo Walburger, "Relación de la Provincia del Darién, escrita en el año de 1748, por el Padre Fray Jacobo Walburger de la Compañía de Jesús, y trasladada de la letra original del mismo Padre", El diablo vestido de negro y los cuna del Darién en el siglo XVIII. Jacobo Walburger y su Breve noticia de la Provincia del Darién, de la ley y costumbres de los Yndios, de la poca esperanza de plantar nuestra fé, y del número de sus naturales, 1748, ed. Carl Henrik Langebaek (Bogotá: Universidad de los Andes / Banco Popular, Fondo de Promoción de la Cultura, 2006) 77. 
—a la sazón también un prestigioso "lere" — iba a morir en próximas calendas. Pudieron determinar que, ante el fatal desenlace pronosticado en los cielos, "Dios estaba vistiendose de luto, y para mostrar su sentimiento a los yndios, mandó a la Luna que tambien se cubriese, y se vistiese de luto".

Así el sacerdote católico no hubiese avalado esta aseveración, el fatal pronóstico fue realizándose de manera inexorable, pues, como él mismo refirió, "pocos dias después se enfermó de Zabandillo mi Captn Andres, lere el mas afamado. Luego empezaron a decir que el Diablo les havia revelado la pura verdad, y que no havia esperanza de que viviese mas, sino que havia de morir sin remedio". ${ }^{10}$ Algunas jornadas después este importante personaje murió y la colectividad entera se vio abocada a realizar de la mano del chamán otra serie de rituales en aras de armonizar de nuevo su conexión con la esfera sobrenatural y evitar así mayores desgracias en su salud colectiva. ${ }^{11}$

Como también lo revela el caso anterior, varios de estos esquemas de conocimiento especializado se caracterizaron por tener al menos tres esferas -interdependientes y complementarias entre sí- de gestación de supuestos conceptuales y de materialización de resultados concretos. Según las pocas "noticias" que sobre este punto dieron los voceros de la Ilustración, para la mayoría de los indígenas el ámbito de la realidad espiritual y el de la natural no estaban escindidos de la realidad social; al contrario, aquellos tres planos se fundían en un único corpus de sentido. ${ }^{12}$ A diferencia de los parámetros de fragmentación epistemológica y de encapsulamiento disciplinar que se estaban dando en la ciencia moderna, los diversos niveles de interpretación de la realidad se interrelacionaban y mutuamente contribuían a formular explicaciones de orden holístico sobre cada uno de los componentes, fenómenos o entidades del cosmos natural y humano que se estuviere analizando.

9. Walburger 78 .

10. Walburger 78 .

11. Para conocer más sobre el papel de los chamanes y su ámbito de intermediación entre el cosmos terrenal y el espiritual en otras culturas amerindias durante los periodos prehispánico y colonial, véase José V. Rodríguez Cuenca y Arturo Cifuentes Toro, “Tequinas, mohanes, piaches y jeques. Los chamanes en el mundo prehispánico de Colombia”. http://www.humanas.unal.edu.co/ colantropos/files/7414/7373/3405/Tequinas_Rodriguez.pdf (22/11/2018).

12. Esta característica de integralidad fue uno de los puntos que más combatieron los ilustrados y fue una constante en todo el continente. Sobre lo ocurrido en el ámbito rioplatense entre los misioneros jesuitas frente a los saberes indígenas, se señala que: “en cada una de las partes de este proceso hubo indígenas alrededor de los misioneros, ya fuera señalándoles qué planta debían recoger y cuáles eran sus beneficios, o bien de qué maneras utilizarlas para curar. Los sacerdotes utilizaron estos conocimientos, desprendiéndolos de lo que consideraron su base 'irracional' [...] Por otra parte, la formación ilustrada les conminaba a rechazar de cuajo aquellas creencias vinculadas a la magia, las ceremonias shamanísticas, así como el uso de sustancias o productos utilizados como talismanes, que se consideraron en general producto de mentes enfermizas". María Silvia di Liscia y Aníbal O. Prina, "Los saberes indígenas y la ciencia de la Ilustración", Revista Española de Antropología Americana 32 (2002): 313-314. 
En este orden de ideas, series completas de representación del mundo y sus significados anexos, que para el siglo XVIII se estaban gestando dentro de la ciencia europea para estructurar sus propios paradigmas científicos y en aras de hilvanar su propio "dispositivo de expropiación epistémica"13 de los saberes de otras sociedades como las de naturaleza / sociedad, lo vivo / lo inerte, lo racional / lo espiritual, lo material / lo inmaterial, cuerpo / espíritu, esencia / apariencia, lo objetivo / lo subjetivo o lo humano versus lo animal o lo vegetal, etcétera, no tenían mucho sentido dentro de los conocimientos logrados por los distintos estratos de la "plebe" virreinal. ${ }^{14}$

Han quedado pocos testimonios de aquella unidad ontológica de referentes epistemológicos. En uno de ellos, un asombrado viajero relataba que los curanderos negros del Chocó pensaban que muchas plantas tenían la facultad del libre desplazamiento por selvas y montañas. Pero no solo eso, al igual que los humanos y animales, algunas de ellas también poseían voluntad autónoma y la capacidad emocional de tener estados psicológicos como odio, amor, miedo, alegría o tristeza. De manera concreta, este cronista anónimo refirió el caso de un "bejuco" silvestre que se movía a su libre albedrío por la zona y que, de vez en cuando, decidía atacar con "rabia", mediante un doloroso aguijonazo, a los desprevenidos paseantes. Sorprendido anotó que "el mobimiento que tiene por sí, parece cosa animada". Pero lo más sorprendente del asunto era, según le advirtieron sus informantes, que "solo con el hombre demuestra su pación [...] y también de experiencia que con ningún animal, aunque lo estropee, no hase movimiento". ${ }^{15}$

Le explicaron que la causa del fenómeno estribaba en que aquella planta, de forma similar a lo que ocurre en un imán con el hierro, se sentía "atraída" por la esencia humana. De allí que

naturalmente sealla compuesto de ciertas materias, que tienen cierta coneccion contraria y atractiva a la naturaleza, y complecion del hombre, y por esto quando le tiene inmediato y recibe

13. Los saberes de los peldaños de poco "orden y decencia" se pasaron por esta matriz dicotómica. Por lo mismo, como lo anota Santiago Castro-Gómez, "resulta claro que la sociología espontánea de la élite neogranadina construía una representación en la que todo conocimiento proveniente de Europa era visto como esencialmente superior al conocimiento producido y transmitido empíricamente por los nativos de América y África [...] El conocimiento producido por ellos no era 'racional', ya que sus experimentos no se dirigían a entender científicamente los procesos de la naturaleza, sino a satisfacer sus propias pasiones". Santiago Castro-Gómez, La hybris del punto cero. Ciencia, raza e ilustración en la Nueva Granada (1750-1816) (Bogotá: Editorial Pontificia Universidad Javeriana, 2005) 193 y 199.

14. Castro-Gómez. En torno a la construcción del modelo discursivo de los "sabios" como élite intelectual hegemónica, véase Renán Silva, Los ilustrados de Nueva Granada, 1760-1808. Genealogía de una comunidad de interpretación (Bogotá: Banco de la República / Fondo Editorial Eafit, 2002).

15. "Razón extensa y verídica de todas las observaciones que se han hecho de todos los árboles, plantas, animales quadrupedos, bolatiles, inceptos, sabandijas y zerpientes venenosas, que la naturaleza por si a criado y fabricado en todas estas dilatadas montañas del Chocó", Estudios Sociales 8-9 (1995): 50. 
su vapor, se pone en movimiento, y luego de que le puede alcanzar buelve contra él la punta que le guía, hasta darle el aujonaso, lo que no verifica con ninguna bestia, porque ninguna es de compuestos tan Nobles y superiores y, por lo mismo, no tienen parte en las materias de que sealla adornado este bejuco, para hacerle mover contra ellos. ${ }^{16}$

De igual forma, los procesos de observación, experimentación, codificación, encuentro y replicación de hallazgos se podían iniciar o aplicar en cualquiera de estos tres órdenes de interpretación (el espiritual, el natural y el social) y en la diversidad de eventos y criaturas que los componían. Es más, aquella ductilidad intelectual para aproximarse a la realidad, la abierta conectividad de sus diversos procesos de discernimiento, la gran movilidad de metodologías y la múltiple utilización de resultados en la vivencia cotidiana fueron percibidas por los voceros de la nueva ciencia metropolitana como una muestra palpable de las "veleidades" que guiaban los saberes del "vulgo" neogranadino.

Y lo eran mucho más, si el agente ilustrado no era el centro del saber o no estaba allí para comprobar la validez o no de los asertos de las "castas". ${ }^{17}$ Cuando José Celestino Mutis se reunió en el mes de julio de 1761 con "señoras criollas, señores criollos y chapetones" para discutir sobre las múltiples formas que tenían los esclavos y los libres "de todos los colores" para conjurar los ataques de las serpientes y otras "alimañas" venenosas que pululaban en las "tierras calientes" del río Magdalena, algunos contertulios refirieron el uso de varias "contras" como fue el caso del "solimán” (al parecer un pequeño emplasto cuyo material primordial era el mercurio) que era "introducido mediante una incisión sobre la picada en el lugar enfermo". ${ }^{18}$

Otros participantes conceptuaron que aquellos sectores lograban "atontar a las culebras" mediante el uso de determinadas hierbas y pócimas magistrales. No faltó tampoco quien aludiera que los saberes adquiridos en este campo eran pura y llana "ficción" y también figuró el que pensaba, como fue el caso de don José Rocha, que en todas estas curaciones intervenían poderes mágicos y hasta un "pacto con el diablo". ${ }^{19}$ Por su parte, el médico gaditano, conceptuó que muchos de esos logros médicos que se ponderaban entre "ignorantes" eran tan solo "vulgaridades" de

16. "Razón extensa" 51.

17. Con base en esta distancia epistemológica, los ilustrados construyeron gran parte de sus narrativas sobre la producción intelectual de diversos grupos sociales. Ángela Pérez, al analizar los relatos de viaje de José Celestino Mutis, advierte que son "testimonios que buscan representar un mundo desconocido con pretensiones de objetividad, pero, en mayor o menor grado, están invariablemente habitados por esa primera persona del autor que se convierte en eje de la realidad visitada [...] El viajero es a la vez representador y representado, reportero y legislador, y en todo esto está inevitablemente narrándose a sí mismo”. Ángela María Pérez Mejía, "Mutis o la trampa de la Mutisia Clematis", Boletín Cultural y Bibliográfico 34.46 (1997):35-36. Sobre la figura del viajero académico del siglo XVIII y XIX, véase Juan Pimentel, Testigos del mundo. Ciencia, literatura y viajes en la Ilustración (Madrid: Marcial Pons, 2003).

18. José Celestino Mutis, Viaje a Santa Fe, ed. Marcelo Frías Núñez (Madrid: Historia 16, 1991) 147.

19. Mutis 147. 
las que se debería desconfiar con ojo avizor. Fue así como en otro evento similar en el que se debatieron las propiedades terapéuticas de las "piedras de Curbinata" (calcificaciones renales o biliares también conocidas como del "inga", "bezares" o "bezoares") para conjurar los efectos de los embates de reptiles y artrópodos, señaló enfáticamente que su aplicación sobre las heridas, su supuesta capacidad de extraer la "ponzoña” inoculada, así como las formulaciones mágicas o "rezos" que acompañaban el tratamiento, no se podían tomar por algo válido; más cuando en este y otros tópicos "yo no creo semejantes noticias mientras no tenga repetidas experiencias propias o de sujeto capaz de decir en la materia, sin dejarse prevenir en las aprensiones del vulgo, y de un vulgo como el de este reino, absolutamente fatuo en asuntos de medicina". ${ }^{20}$

\section{Métodos de evaluación de la realidad}

Cuando se analizan los diversos métodos empleados para construir estas matrices de pensamiento diferencial, lo primero que sale a flote es que sus autoridades intelectuales exploraban el universo circundante de una forma igualmente abierta y multidimensional. No solo combinaban en una misma indagación los componentes mágico-espirituales, las implicaciones provenientes del medio ambiente o las incidencias por las que estaba atravesando el medio social interno y externo a su colectividad, sino que ellos mismos — cuando arribaban al espectro práctico de su quehacer - se involucraban en los problemas investigados a través de una experiencia directa de contacto guiada por el uso sistemático de todos los sentidos.

Ello les confería un alto grado de compenetración con los eventos analizados; diluía la distancia entre sujeto cognoscente y objeto conocido y de esta íntima relación se percató (lo que no quiere decir que la avalara), entre otros, Alexander von Humboldt durante su periplo por la Orinoquía a comienzos del siglo XIX. ${ }^{21}$ Cuando arribó en compañía del botánico Aimé Bonpland a las inmediaciones de la primera catarata del río Juagua y por los playones auríferos del risco del Cuchivano, refirió que las etnias indígenas locales habían recabado un caudal enorme de

20. Mutis 137. Para profundizar en la obra de Mutis y su complejo proceso de contacto con pares intelectuales de las élites en Europa y América, véase Olga Restrepo Forero, "Naturalistas, saber y sociedad en Colombia", Historia social de la ciencia en Colombia, t. 3, eds. Luis Carlos Arboleda y otros (Bogotá: Colciencias, 1993) 49-130; Santiago Díaz-Piedrahita, Matís y los dos Mutis. Orígenes de la anatomía vegetal y de la sinantercología en América (Bogotá:Academia Colombiana de Ciencias Exactas, Físicas y Naturales, 2000).

21. Durante el siglo XVIII en España y sus colonias los paradigmas modernos todavía pugnaban con los antiguos. En el ámbito médico, la doctrina alopática coexistía con el galenismo humanista que separaba el saber teórico de los "oficios mecánicos" y subvaloraba a estos últimos. María Eugenia Osorio Oliveros, "La botica neogranadina de la Compañía de Jesús: un laboratorio para explorar prácticas médicas en la provincia de Santafé, primera mitad del siglo XVIII", Historia y Memoria 6 (2013):143-169; Andrés Prieto, Missionary Scientists. Jesuit Science in Spanish South America, 1570-1810 (Nashville:Vanderbilt University Press, 2011). 
conocimiento sobre las distintas especies botánicas que crecían en la región. Para lograrlo,

\begin{abstract}
los indios hacían profundas incisiones en los troncos de los árboles con sus grandes cuchillos, para llamar nuestra atención sobre la belleza de las maderas, rojas y amarillas doradas. Nos mostraron una planta de flores compuestas que llega a tener 6,5 metros de altura [...] y la sangre de drago indígena, una especie aún no catalogada de euforbia, cuyo jugo, rojo y astringente, se emplea como reforzante de las encías. Distinguían las especies por el olor, y más aún, mascando las fibras leñosas. ${ }^{22}$
\end{abstract}

Los documentos dejados por la élite ilustrada evidenciaron, además, otras constantes generales - exceptuando especificidades culturales que los textos no brindan en muchos casos - que articularon el componente fáctico de la producción intelectual de las "castas". Mostraron que muchos de sus avances se gestaron igualmente a partir de un proceso sistemático de observación de los fenómenos del medio físico-biológico que habitaban. Así, cuando navegaba el 16 de enero de 1761 por el río Magdalena, José Celestino Mutis presenció de primera mano el profundo cúmulo de saber que sus navegantes zambos tenían sobre los afluentes, las corrientes, remolinos, meandros, rápidos y demás elementos hidrológicos de aquella enorme y compleja estrella fluvial.

Frente a una repentina inundación acontecida por los lados del poblado de Cantagallo, tuvo, como él mismo indicó, "el gusto de ver cómo conocieron los bogas, en la naturaleza del agua que bajaba por el río, cuál de los pequeños ríos que se descargan en el Magdalena ocasionaba la creciente. En efecto, concluyeron que el Sogamoso y el Carare habían enviado el agua". ${ }^{23}$ Siete días después, por los lados de la desembocadura del río Nare en el principal curso acuático de la región, se percató de que una densa neblina se levantaba y explayaba únicamente por la orilla derecha. Preguntó sobre el particular fenómeno y consignó que:

aquello significa que Nare va creciendo. Causóme alguna novedad esta señal y la certidumbre con que los bogas afirmaban la proposición. Pregunté a muchos otros lo mismo y todos convinieron en el efecto, que tienen averiguado por una constante experiencia [...] todos me respondieron, en su tosca filosofia: porque las aguas frías se mezclan con las calientes. No me desagradó la respuesta. ${ }^{24}$

De aquel mecanismo para acopiar y sistematizar datos relevantes en la naturaleza circundante se derivaban experimentaciones, formulación de conceptualizaciones y, en algunas ocasiones, el desarrollo de aplicaciones concretas para el diario

22. Alejandro de Humboldt, Del Orinoco al Amazonas. Viaje a las regiones equinocciales del Nuevo Continente (Barcelona: Booket, 2005) 91.

23. Mutis 119.

24. Mutis 128. 
vivir de las comunidades involucradas. Tal fue el caso de los saberes agrícolas asociados a los ciclos biológicos de las plantas, conocidas - al menos en la zona norte del litoral Pacífico- como "indicios". De allí que en las inmediaciones de Lloró (Provincia de Citará, gobernación del Chocó) en el mes de octubre, el "churima” (Inga spuria e Inga choensis), un “árbol alto y coposo” que produce una "especie [...] de guamos pequeños o vainas prolongadas, más largas al duplo que la de chícharos o garbanzos", preludiaba para los indígenas chocoes la nueva siembra del maíz al estar en este mes sus frutos en plena "sazón". ${ }^{25}$

En el caserío aledaño de Beberá, el mecanismo de esta "simple astrología", como la denominó el viajero anónimo que circundó la cuenca del Atrato alrededor de la década de 1770, era el siguiente: "se nombran [los indígenas] del Cedro por que determinan y hacen sus sementeras de maíz por el mes de mayo, estación en que aquel árbol [Cedrela odorata], despojándose de sus hojas, se llena o produce ciertos pimpollos de frutilla". ${ }^{26}$ Pero este proceso de indagación de la realidad también se combinaba con la aguda inspección de los patrones y hábitos de vida de diversas especies animales (alimentación, cría, refugio, lugares de residencia, técnicas de depredación y defensa, etcétera).

Fue así como el científico francés Charles M. de la Condamine - tan poco dado a valorar la capacidad intelectual de los grupos amerindios con los cuales se topó en sus recorridos por la Real Audiencia de Quito y el río Amazonas en el primer tercio del siglo XVIII- conoció el verdadero origen de la utilización de las diversas especies de quina como un efectivo anti febrífugo en seres humanos. Contrario a quienes afirmaban que este trascendental evento fue un hallazgo de la ciencia europea, reseñó que

el uso de la Quina era conocido de los Americanos antes de serlo de los españoles [... En quanto al modo de hacer uso de ella se dice que infundian en agua por espacio de un día la corteza quebrantada, y separada del residuo, la daban á beber á los enfermos [...] Según una antigua tradición (de cuya verdad no salgo por fiador) los Americanos debieron el descubrimiento de este remedio á los Leones [Panthera onca o jaguar], de quienes aseguran algunos Naturalistas que padecen una especie de fiebre intermitente. Dicen, que haviendo observado los de aquel pais que estas fieras comían las cortezas del árbol de la Quina, la usaron en las calenturas accesionales bastante comunes allí, y entonces conocieron su virtud saludable. ${ }^{27}$

Otro caso similar lo relató Pedro Fermín deVargas cuando se refirió a los logros de los curanderos negros libres y esclavos en la fabricación de sustancias capaces de contrarrestar los efectos del veneno inoculado por determinadas especies de

25. "Descripción superficial de la Provincia del Zitará, con sucinto relato de sus poblaciones, establecimientos de minas y bríos de mayor nombre", Relaciones geográficas de la Nueva Granada. Siglos XVI a XIX, ed.Víctor Manuel Patiño (Cali: Instituto Vallecaucano de Investigaciones Científicas, 1983) 429.

26. "Descripción superficial" 429.

27. Charles M. de la Condamine, Viaje a la América Meridional por el río de las Amazonas. Estudio sobre la quina, eds. Antonio Lafuente y Eduardo Estrella (Quito:Abya-Yala, 1993) 189-190. 
serpientes. Anotó que sus aportes en la materia a pesar de provenir de "mentes bárbaras" habían nacido de observar "cuidadosamente sus usos [de la naturaleza, y por ello habían] descubierto mil secretos preciosos, que la medicina no se há desdeñado de colocar después en sus fastos". ${ }^{28}$ Por este mismo factor, y diferenciándose de muchos de sus contemporáneos, estuvo dispuesto a ver algún "rastro" de "ciencia" en las mentes de los oficiantes médicos locales y para sustentar su afirmación citó la compleja tarea de creación intelectual que llevó a la obtención del compuesto antiofidico elaborado a partir de la conjunción de varios "bejucos" conocidos de manera genérica como de "guaco". Así,

del número de estas invenciones es sin duda alguna una de las más útiles el famoso preservativo de culebras, que con el nombre de Bejuco de el Guaco, se vá extendiendo por todo el Reyno. Los Negros de la provincia del Chocó fueron los primeros según se cree, que observaron el modo con que el Guaco [Herpetotheres cachinnans o halcón reidor], caza y persigue las culebras de los países cálidos, para hacer de ellas su pasto principal; y habiendo descubierto que quando buenamente no las puede matar [el ave] se vale de las hojas de un bejuco con que las adormece. Hicieron luego [los curanderos] sus tentativas, y por este medio descubrieron que el zumo de aquella planta no solo cura la mordedura de estos reptiles, sino que preserva también de su veneno á todos aquellos que lo toman con frecuencia. ${ }^{29}$

Mas la codificación creativa de las circunstancias propias de la cotidianidad humana tampoco quedó por fuera de las "reflexiones de los salvajes". Gracias a ella, se logró el descubrimiento de las virtudes antihemorrágicas del "palo de sangre" (Columnea dimidiata), ponderadas luego en España por Mutis y otros autores en sus informes enviados a la metrópoli, aunque se colocaban a sí mismos como el centro indiscutido del descubrimiento científico. Todo aconteció, según la tradición en boga en estos momentos en la costa Caribe, cuando

habiéndose un hombre en el monte herido un pie, y cortándose todas las venas, aunque este se ligó a la parte de arriba fuertemente, aunque en la herida se puso yesca ensendida, para con el fuego cavecear las venas, y aunque se amarró con un pañuelo fuertemente no le paró la sangre [...] Y en la distancia del monte, viéndose muy fatigado se sentó al pie de un árbol, cuyas raíces sobresalían de la tierra en donde fixó el pie, y observó, que la sangre sele contubo enteramente, pero lo atribuyó, que sería por haver contenido el mobimiento del paso, y bolviendo a tomar su destino sele soltó más copiosamente la sangre, y aquí fue que

28. Pedro Fermín de Vargas, "Nota sobre las serpientes”, Papel periódico de la ciudad de Santafé de Bogotá (Bogotá) 30 de septiembre de 1791: 201.

29. Vargas 201. Sus efectos terapéuticos siguen siendo investigados por la ciencia occidental moderna. Se elabora a partir de un concentrado de los bejucos de la familia Caesalpiniaceae y, por lo general, incluye de manera conjunta o por separado a varias especies distintas como las conocidas desde aquel entonces como "guaco morado" (Mikania guaco) y "guaco negro" (Aristolochia pilosa). 
ya le entró cierta refleción, y suspendiendo el paso bolvió al árbol, y puso pie sobre las raises, y luego sele estancó [...]Y con esto quedó descubierta la virtud de este palo tan excelente. ${ }^{30}$

Algunas notas reflejaron que las distintas autoridades científicas locales también hacían acopio de instrumental adecuado para medir, pesar, cuantificar cantidades y estandarizar procesos de indagación de la realidad. De ello fueron testigos Humboldt y Bonpland al momento de inquirir por la fabricación del veneno curare cuando llegaban al caserío de la Esmeralda (situado en la confluencia del Orinoco con el río Guaviare). De voz de sus interlocutores indígenas conocieron que allí se confeccionaba dicho insumo a partir de la decocción del "bejuco del Mavecure" (Strychnos sp.) recién macerado o secado al sol, adobado con el zumo vegetal de un árbol llamado localmente como ciracaguero - de consistencia muy viscosa y con coloración parecida al alquitrán- que facilitaba que el veneno se adhiriera a los mortíferos dardos que eran impulsados mediante largas cerbatanas. Esta fórmula competía con varias otras como las desarrolladas entre las etnias piraroa y los sálivas, pero la lograda ahí - y en la zona de Mandava- era la más apreciada por su evidente letalidad. Para lograrla, su artífice se valía de un complejo instrumental y a pesar de su reticencia a validar sus experimentos los viajeros extranjeros se vieron forzados a reconocer que

aquel hombre era el químico del lugar. En su casa encontramos grandes cacerolas de arcilla para cocer los jugos de las plantas; vasijas más llanas que, por su mayor superficie, activan la evaporación; hojas de platanero enrolladas en espiral para filtrar los líquidos, que contienen sustancias fibrosas. En aquella choza, habilitada para laboratorio, reinaban un orden y una limpieza extremados. ${ }^{31}$

Sobre los circuitos de generación y transmisión de conocimiento, el indígena que los puso al tanto de este adelanto les indicó que "el curare, cuya elaboración entre nosotros pasa de padre a hijo, es mejor que todo lo que vosotros sabéis hacer allá (del otro lado del mar). Es el jugo de una planta que mata en silencio (sin que se sepa de dónde viene el tiro)". ${ }^{32} \mathrm{Y}$ al comunicarse y perfeccionarse con el paso del tiempo, el acervo de conocimiento logrado se renovaba y engrandecía en cada generación, con lo cual se conformaban verdaderos protocolos de gestación y puesta en común de saberes científicos que no eran - ni lo son hoy en día- patrimonio exclusivo de la ciencia moderna de corte occidental.

\section{0. "Razón extensa" 54.}

31. Humboldt 355.

32. Se desconoce la etnia indígena a la cual pertenecía el informante, ya que en esta misión los sacerdotes habían congregado, además de algunos mestizos y varios zambos, mulatos y "otras gentes de color", al menos a tres grupos indígenas distintos que hablaban sendas lenguas diferentes, a saber, idapaminar, catarapen y maquiritare. Humboldt 353 y 355. 


\section{3. “Idiomas campesinos” y autoridades científicas}

Si se ahonda un poco más en esta última faceta del quehacer científico del "común", se puede apreciar que los textos coloniales también reflejan —así fuera para descalificarlos - la existencia de verdaderos "idiomas campesinos", compuestos de "jerigonzas incomprensibles" que se hilaban por medio de "voces vulgares". Ellas les servían a sus portadores para nombrar a las distintas criaturas y fenómenos del universo, para ordenar métodos y conceptos aplicados durante sus indagaciones, para formar y reproducir en el tiempo comunidades intelectuales, así como para insertar sus hallazgos en el contexto sociocultural y hacerlos inteligibles - y, en algunos casos, utilizables - a los restantes miembros de sus respectivas colectividades.

En este sentido, los documentos revelan la presencia de por lo menos tres tipos diferentes de discursos especializados y, por ende, de igual número de circuitos de difusión y transmisión de los logros conceptuales y prácticos desarrollados por las distintas autoridades intelectuales. El primero de ellos poseía un carácter restrictivo tanto en su elaboración como en su grado de socialización, y, por lo mismo, era conocido tan solo por algunos pocos iniciados en aquellas estrategias crípticas de enunciación de saberes. En este apartado los conocimientos de orden mágico-espiritual asociados a la exploración astronómica y geográfica, a las prácticas médicas, faenas de caza y horticultura, desarrollos de ingeniería, clasificación taxonómica, etcétera, resultaron especialmente reveladores.

Estos conocimientos estaban a cargo de personajes con alta cualificación intelectual. Aunque los ilustrados los vieran tan solo como simples "agoreros", "embusteros" o "zahoríes", eran tomados — con reverencia y, en igual medida, con temor- como verdaderos agentes de pensamiento dentro de su propia comunidad de referencia.Tal fue el caso de los "piaches" o chamanes existentes en varias de las culturas indígenas de la Orinoquía que visitó el misionero jesuita Pedro Salvador Gilij a comienzos de la segunda mitad del siglo XVIII. ${ }^{33}$ Tal como anotó en su extenso tratado, estos personajes no solo conocían los aspectos prácticos de distintos ramos del saber, como fue el ámbito de las "artes de curar", sino que jugaban un importante papel dentro de "las cosas aún más abstrusas y más ocultas a las miradas" ${ }^{34}$ Entre ellas figuraban vaticinar eventos futuros, viajar por diversos mundos y niveles cosmogónicos, transformarse y entrar en contacto con sus diversas criaturas, conjurar las fuerzas primigenias de la naturaleza (para detener tormentas

33. Felipe Salvador Gilij, Ensayo de Historia Americana, t. 2 (Caracas: Academia Nacional de la Historia, 1965) 89. Gilij, al seguir su pasión por los estudios lingüísticos, pudo determinar que este apelativo era una traducción fonética literal al español del término tamanaco "pchiachi". Los maipures los denominaban "marirri" y los "parecas" les decían "yachi". La primera acepción se generalizó y así ha llegado hasta el presente. La antropología ha analizado estas y otras instituciones culturales en el presente, pero nos corresponde a los historiadores brindar los referentes que las confirman como prácticas ancestrales.

34. Gilij 89. 
o propiciar lluvias y crecientes fluviales, entre otras múltiples alternativas) o traer y llevar mensajes a las divinidades. ${ }^{35}$ Para recabar el conocimiento necesario debían someterse a una larga y compleja labor de formación intelectual y física que los distinguía de los restantes miembros de sus colectividades. De allí que "ninguno habla las lenguas mejor que ellos", que fueran "elegantes de espíritu e ingeniosos en el decir" y que conocieran "las tradiciones antiguas de los pueblos y otras cosas no despreciables". 36

Pero también eran expertos en "ensalmos que saben sólo ellos" y "pronunciando versos" era como "saltan los piaches el infierno y pasan al otro lado". ${ }^{37}$ Todos estos conocimientos se transmitían de forma restringida a través de circuitos de aprendizaje que fluían desde maestros consagrados hacia discípulos cuidadosamente seleccionados y únicamente por su intermedio estos saberes llegaban a las comunidades. Pero estas últimas eran depositarias pasivas de sus avances y existía poca posibilidad de que los miembros no iniciados pudieran replicarlos por cuenta propia. El mismo misionero italiano fue testigo de la conformación de aquellos cenáculos cerrados de saber y sobre ellos afirmó que:

desde pequeños (y Dios sabe con qué medios diabólicos) van todos a la escuela y son instruidos los muchachos en el arte de curar por algún piache famoso que han sido por él vigilados durante tiempo y por su malicia o habilidad son creídos aptos para el piachismo. Les dan lecciones en espesas selvas, lejos siempre de la vista del otro, y al cabo de algunos años, he aquí que son de repente piaches y doctores. ${ }^{38}$

Sin embargo, en esta y en muchas otras sociedades del "común" se daba también una segunda vía - complementaria o alterna a la anterior- que permitía la organización, transmisión y disfrute comunitario de otra porción significativa del cúmulo de saber socialmente disponible. En este otro caso se trataba de conceptos y producciones que estaban en manos de autoridades intelectuales que desempeñaban su actividad desde un sustrato de conocimiento ubicado no necesariamente en la esfera sobrenatural. Continuando con la problemática de la salud / enfermedad, pero en esta ocasión referido al horizonte cultural de los grupos negros, existían en el siglo XVIII no solo "brujos", "magos" o "hechiceros" que trataban

35. Al dar cuenta de algunas de estas facultades, un indígena maipure le contó que el cacique, a la par piache de su parcialidad, de nombre Carávana, poseía el poder de subir "todos los días al cielo". Una vez en este otro plano de la realidad, "ve allí a Dios [...] que da de comer sus alimentos a los tigres, como las mujeres echan maíz delante de las gallinas". El sacerdote contempló cómo varios de los chamanes más poderosos se vanagloriaban, además, de "transformarse en tigres y en otros feroces animales [...] Se jactaba otro de caminar por debajo de tierra desde el lugar de las misiones jesuíticas hasta las bocas del Orinoco. Este mismo (tanta es su orgullosa vanidad) decía que había visto la boca del infierno, que era muy estrecha y que por sí misma no daba entrada a los hombres". Gilij 94-95.

36. Gilij 95.

37. Gilij 95.

38. Gilij 91. 
enfermedades (para curarlas o para causarlas) desde el ámbito metafísico, sino "sobijeros" encargados de tratar lesiones musculares y óseas tan frecuentes en los reales de minas, "curadores de culebra" especializados en elaborar "contras" para intervenir los accidentes ofidicos, así como "sangradores" que realizaban pequeñas cirugías y "hierbateros", expertos en tratar toda clase de afecciones con productos vegetales o de origen animal y mineral. ${ }^{39}$

Todos ellos, conjuntamente con las "parteras", conformaban otro frente de intervención — sin preparación esotérica en la mayoría de los casos- encargado de la atención médica entre estos estamentos (y aun entre los blancos que también los consultaban de manera subrepticia) y se agruparon, desde la perspectiva del colonizador, en la categoría genérica del "curandero(a)". Sus logros se transmitían de manera más abierta que en el caso anterior y fluían no solo de maestro a aprendiz, sino de padre a hijo, de familia a familia, de caserío en caserío e incluso de una comunidad étnica a otra distinta. De la eficacia de algunos de sus recursos terapéuticos y farmacológicos dieron cuenta autores de la Ilustración y, para señalar uno de esos eventos, fue muy ponderado el tratamiento dado en ambas costas del virreinato a diversos tipos de filariosis o culebrilla que asolaban a las poblaciones locales.

En la gobernación de Cartagena, Antonio de Ulloa presenció su accionar y al comprobar su efectividad no dudó en escribir en sus notas de viaje que "la gente del país cura con destreza esta enfermedad". " Para lograrlo, el tratante aplicaba sobre el forúnculo donde habitaba el parásito un "llamativo"-constituido en un emplasto fabricado con hierbas y otros productos naturales - que irritaba la lesión. Acto seguido, ella se friccionaba con aceites y al otro día se encontraba que la piel estaba abierta y que por su "boca" asomaba la blanquecina y sinuosa cabeza del gusano nemátodo. Para fijarla y extraer todo el cuerpo del agente invasor, se ataba luego

a él una hebrita de seda, la envuelven en un naipe enroscado hasta que aquel niervecillo quede algo sujeto a él; vuelven a dar la untura como en el primer día y lo dejan hasta otro, que, descubriéndolo, continúan enrollando en el naipe lo que ha vuelto a salir y, así, prosiguen hasta que sale todo y queda libre la persona. Tienen gran cuidado en que no se rompa antes de estar toda afuera, porque dicen que, esparciéndose aquel humor que encierra en los del cuerpo, hace producir gran cantidad de ellas, y entonces es peligrosa la cura. ${ }^{41}$

La tercera alternativa de codificación y de transmisión de saberes también podía correr a cargo de especialistas en cada disciplina, aunque gran parte de sus contenidos nacían de personas sin una instrucción especializada. Se gestaba a través del proceso individual de ensayo y error de posibles alternativas, cuyos resultados se comunicaban de voz en voz. Circulaban sin ninguna restricción y una muestra de

39. Jaime Andrés Peralta Agudelo, "Oficiantes del bienestar humano. Curanderos negros en el Pacífico colonial”, Todos somos historia, t. 2, ed. Eduardo Domínguez (Medellín: Canal U, 2010) 321-342.

40. Antonio de Ulloa, Viaje a la América Meridional, t. 1, ed. Samuel Lladó (Madrid: Dastin, 2002) 87.

41. Ulloa 87-88. 
aquella faceta de la "sabiduría del vulgo" se explicó en el Curioso, erudito y mercantil de la ciudad de Santafé de Bogotá al momento de tratar dentro del "calendario rural" las variadas posibilidades de cultivo que ofrecían los diversos parajes del virreinato. Al referir en su número 35, correspondiente al 13 de octubre de 1801, la destreza de los habitantes del litoral del Pacífico para "sazonar" el suelo poco fértil de lo que hoy se conoce como selva húmeda tropical, se advirtió que, contrario a lo ejecutado en el entorno andino,

en los lugares, donde llueve perennemente como en la Provincia del Chocó, y toda la costa Occidental del Reyno, no se quema [...] Se siembra en aquellos montes, sin otra operación, que cortar las ramas baxas, matas y arbustos, esparciendo a un mismo tiempo el grano, despues de lo qual se derriba el monte, sobre el maíz ya nacido. Los jugos que debían alimentar aquella selva refluyen y se emplean en los sembrados. ${ }^{42}$

La oralidad era, pues, el mecanismo sustancial que portaba la memoria científica de los "rústicos" neogranadinos. Al mostrar su sorpresa por la permanencia intergeneracional de estos aprendizajes, Felipe Salvador Gilij consignó que era evidente que los conocimientos especializados circulaban y se perpetuaban en el tiempo a pesar de que en sociedades "salvajes" como las indígenas del oriente virreinal no existían "letras, ni libros, ni papel, ni tinta". ${ }^{43}$ Sin embargo, este medio de circulación de saberes le confería ciertos determinantes a aquellos sistemas de conocimiento alternativos que intervenían en la realidad natural y social y que en unos casos limitaban y en otros potenciaban la amplitud espacial de la difusión de los saberes.

Al estar constreñido el acervo de convenciones y significados dentro de un universo idiomático concreto, se podría limitar la comprensión de supuestos conceptuales o la utilización de descubrimientos por personas ubicadas al margen de cada barrera lingüística y, de igual manera, el intercambio y enriquecimiento de conocimientos se obstaculizaba entre aquellos que provenían de sociedades con referentes culturales distintos (cuyo vehículo transportador era la lengua). Esta impronta de universalidad restringida fue percibida negativamente por los ilustrados y, al reafirmar aquella limitación, Jorge Tadeo Lozano advirtió que, pese a algunos logros nacidos del contacto directo con la naturaleza, poco de utilidad científica se podía extraer de "campesinos zafios que ignoran el modo de

42. "Continúa el calendario rural, sobre los trabajos de campo en los meses de Diciembre, Enero y Febrero", Correo Curioso, erudito y mercantil de la ciudad de Santafé de Bogotá (Bogotá) 13 de octubre de 1801: 160. Este sistema de preparación de suelos se denomina en la actualidad como "tumba y pudre" y ha sido la base de los sistemas de agroforestería utilizados por las comunidades afrodescendientes del área. Por lo general, las parcelas se desmontan, cortan, siembran y se ponen en utilización durante unos cinco años. Posteriormente se van remplazando por otras que se roturan cerca de allí y así — tras unos 15 años de rotación de terrenos- la inicial logra una regeneración suficiente con vegetación nativa. Cuando esto se logra, se reinicia el ciclo y así sucesivamente.

43. Gilij 99. 
explicarse y carecen de criterio para despreciar patrañas y preocupaciones en que quedan como anegadas sus noticias". ${ }^{4}$

Sin embargo, y como prueba contraria, han quedado referencias que señalan el asiduo contacto que se daba entre los saberes provenientes de distintos estamentos sociales. Para citar uno entre muchos otros casos, cuando un viajero anónimo recorrió el Chocó se percató del profundo conocimiento de especies zoológicas y botánicas que habían producido de manera mancomunada los libres, esclavos, mestizos e indígenas de esa gobernación. Fruto del intercambio de conceptos, métodos y resultados desarrollaron — entre otros frentes de aplicación — varias fuentes nutricionales conjuntas. Por ejemplo, "Yguanas, que a modo de lagartos seallan de todas clases, y en general, y los Negros y Yndios las casan y comen sin recelo [...] Tortugas se hallan de todas clases, las aprecian mucho los Negros y Yndios, y los huevos los tienen por un gran regalo". ${ }^{45}$

De igual forma, al expresarse los resultados en una terminología de uso común, aquella "vana filosofia" no conducía - como sí ocurría en la ciencia moderna europea - al reforzamiento de la distancia entre gestores y receptores del saber científico. Al contrario, aunque tal vez con la única excepción de las formulaciones cifradas propias del terreno espiritual, el lenguaje y la experiencia social compartidas entre ambos polos del saber propiciaba una expedita circulación, comprensión y utilización de resultados. Los criterios de clasificación y enunciación taxonómica resultaron particularmente esclarecedores sobre este particular, pues, al no desligarse de la producción lingüística de los restantes componentes sociales, las distintas nomenclaturas asignadas a animales y plantas por recursos metafóricos y metonímicos siguieron operando por generaciones dentro del medio cultural en el cual se habían gestado (a diferencia de la utilización del latín y de la categorización unívoca propia del sistema binominal linneano).

$\mathrm{Su}$ apropiación y uso definitivos no estaban, por ende, circunscritos a una pequeña "cofradía de sabios" como les gustaba llamarse a sí mismos a los académicos ilustrados. Fue así como el mismo Lozano se topó con que los pobladores de varios sitios andinos le referían indistintamente la irrupción en sus parcelas de varias especies de "langostas" (insectos del orden Orthoptera) que "el vulgo conoce con los nombres de Saltagatos, Caballitos del diablo, etcétera". ${ }^{46}$ Conocían a la par muchos de sus hábitos de vida y varias formas de controlar su irrupción como plagas en los terrenos cultivados. Sin embargo, en lugar de intentar comprender los criterios de clasificación y los conocimientos asociados a aquellas denominaciones, propugnó para que se recodificaran según los cánones de la clasificación morfológica propuesta por las academias europeas. Más aun, hasta cuando no se hiciera este proceso de suplantación de contenidos trasvasándolos

44. Jorge Tadeo Lozano, "Memoria sobre las serpientes", Semanario del Nuevo Reyno de Granada, t. 1 (Bogotá: Biblioteca Popular de Cultura Colombiana, 1942) 124.

45. "Razón extensa” 80.

46. Lozano 125. 
a informes escritos y a "lenguas cultas" que pudieran validarse al otro lado del Atlántico (al menos en los centros del poder virreinal), aquellos saberes locales no se debían incorporar a la ciencia zoológica o a las técnicas agrícolas del momento.

Aunque situados en similar orilla intelectual, algunos autores dentro de las élites del periodo lograron percibir (no necesariamente reconocer) que varias de aquellas clasificaciones taxonómicas no eran "delirios" caóticos nacidos de meras "impresiones de ánimo", sino que obedecían a un riguroso proceso de observación y estudio de condiciones morfológicas o etológicas y, por lo mismo, se valieron inclusive de ellas para emprender sus propios trabajos de investigación. Al reseñar los nombres que se le asignaban a las aves en las inmediaciones de Cartagena, Antonio de Ulloa encontró, para citar un caso, que el epíteto aparentemente incomprensible de "predicador" que recibía una especie de tucán de la costa Caribe (Ramphastos sulfuratus brevicarinatus) se debía a que "puesto en algún árbol, donde esté más alto que sus compañeros, cuando duermen, hace un ruido en que parece que prorrumpe algunas palabras y lo esparce a todos lados para que las aves carniceras no se atrevan, confiadas del silencio, a hacer garra en las de su especie". ${ }^{47}$

\section{Palabras finales}

En notas al margen de los escritos que registran de manera subrepticia los conocimientos de la gente "común" durante la Colonia, resulta evidente la existencia de múltiples parámetros para explorar, nombrar, ordenar, relacionar e interpretar los diferentes fenómenos, eventos y seres que componían la realidad social y natural de distintos entornos del virreinato. Esto es apreciable pese al ocultamiento deliberado que las élites coloniales —en especial las que se autodenominaban a sí mismas como "ilustradas" - hicieron de los sistemas de conocimiento de los estamentos ubicados por debajo de su estrato social, así como de sus métodos, productos y aplicaciones prácticas.

Fluyeron en diversos circuitos del saber local y regional y, con el vasto y complejo universo de conocimiento elaborado por cada uno de estos grupos humanos (todavía por estudiar en su gran mayoría), se afrontaron diversas problemáticas cotidianas. Asimismo, se generaron alternativas de bienestar comunitario, se validaron otras fuentes de autoridad intelectual y se allanó de esta forma la construcción de una historia alterna o, cuando menos, diferente en muchos sentidos a la versión que quiso implantar el sistema colonial.

Al contemplar precisamente tal diversidad de alternativas de conocimiento, el vocero de la cultura dominante - y en una curiosa paradoja epistemológica del contexto ilustrado - se valió en un primer momento de los informantes nativos y de sus métodos de representación y apropiación del mundo para entender la diversidad del medio americano que estaba recorriendo. Se apropió incluso de algunos de los supuestos que consideró "útiles” para sus propios estudios, aunque los trató

47. Ulloa 99. 
de reducir, traducir y homologar bajo sus propios parámetros de referencia cultural. Pero simultáneamente vio en gran parte de estos sistemas de conocimiento alternos una clara amenaza a su propio universo de vida y a su propia matriz de realidad y se amparó — entre otras herramientas de dominación cultural- en los mecanismos de intervención colectiva propios de la ciencia moderna europea. De esta manera, construyó una dicotomía entre la "civilización” y la "barbarie", unívoca y con pocas alternativas de contacto entre ambos polos de la ecuación, que le permitió buscar la anulación definitiva de aquellos sentidos que se opusieran a sus propios intereses de supremacía económica, social y política.

De allí que gran parte de los contenidos que se salieran de su limitado campo de experiencia, creado y nacido en un contexto muy distinto al neogranadino, fue tildado de crasa "ignorancia" o de simple "superchería" que se debía olvidar cuanto antes para salir del "atraso" y superar la "oscuridad de pensamiento" que, en su concepto, campeaban en estas lejanas tierras. Mas en estas pugnas por lograr la subordinación de la naturaleza y de las gentes que las habitaban no siempre la "luz de la razón" occidental salió triunfante, y fue gracias a esto que gran parte del legado de saber del "común" del pasado ha contribuido a gestar el cariz de diversidad multiétnica y cultural de la sociedad colombiana del presente.

\section{Fuentes}

\section{Impresas}

"Razón extensa y verídica de todas las observaciones que se han hecho de todos los árboles, plantas, animales quadrupedos, bolatiles, inceptos, sabandijas y zerpientes venenosas, que la naturaleza por si a criado y fabricado en todas estas dilatadas montañas del Chocó”. Estudios Sociales 8-9 (1995): 41-84.

"Descripción superficial de la Provincia del Zitará, con sucinto relato de sus poblaciones, establecimientos de minas y bríos de mayor nombre". Relaciones geográficas de la Nueva Granada. Siglos XVI a XIX. Ed.Víctor Manuel Patiño. Cali: Instituto Vallecaucano de Investigaciones Científicas, 1983.

Gilij, Felipe Salvador. Ensayo de Historia Americana. Tomo 2. Caracas: Academia Nacional de la Historia. 1965.

Humboldt,Alejandro de. Del Orinoco al Amazonas. Viaje a las regiones equinocciales del Nuevo Continente. Barcelona: Booket, 2005.

La Condamine, Charles M. de. Viaje a la América Meridional por el río de las Amazonas. Estudio sobre la quina. Eds. Antonio Lafuente y Eduardo Estrella. Quito: Abya-Yala, 1993.

Lozano, Jorge Tadeo. "Memoria sobre las serpientes". Semanario del Nuevo Reyno de

Granada.Tomo 1. Bogotá:Biblioteca Popular de Cultura Colombiana, 1942. Mutis, José Celestino. Viaje a Santa Fe. Ed. Marcelo Frías Núñez. Madrid: Historia 16, 1991.

Santisteban, Miguel de. Mil leguas por América. De Lima a Caracas, 1740-1741. Diario de don Miguel de Santisteban. Bogotá: Banco de la República, 1992. 
Ulloa, Antonio de. Viaje a la América Meridional.Tomo 1. Ed. Samuel Lladó. Madrid: Dastin, 2002.

Walburger, Jacobo. "Relación de la Provincia del Darién, escrita en el año de 1748, por el Padre Fray Jacobo Walburger de la Compañía de Jesús, y trasladada de la letra original del mismo Padre". El diablo vestido de negro y los cuna del Darién en el siglo XVIII. Jacobo Walburger y su Breve noticia de la Provincia del Darién, de la ley y costumbres de los Yndios, de la poca esperanza de plantar nuestra fé, y del número de sus naturales, 1748. Ed. Carl Henrik Langebaek. Bogotá: Universidad de los Andes / Banco Popular, Fondo de Promoción de la Cultura, 2006.

\section{Periódicos}

Correo Curioso, erudito y mercantil de la ciudad de Santafé de Bogotá (Bogotá) 1801.

Papel periódico de la ciudad de Santafé de Bogotá (Bogotá) 1791.

\section{Bibliografía}

Cadelo Buitrago, Andrea. "Hábito e ideología criolla en el Semanario del Nuevo Reino de Granada”. Pensar el siglo XIX. Cultura, biopolítica y modernidad en Colombia. Ed. Santiago Castro-Gómez. Pittsburgh: Biblioteca de América / Instituto Internacional de Literatura Iberoamericana, 2004.

Castro-Gómez, Santiago. La hybris del punto cero. Ciencia, raza e ilustración en la Nueva Granada (1750-1816). Bogotá: Editorial Pontificia Universidad Javeriana, 2005.

Di Liscia, María Silvia y Aníbal O. Prina. "Los saberes indígenas y la ciencia de la Ilustración”. Revista Española de Antropología Americana 32 (2002): 295-319.

Díaz-Piedrahita, Santiago. Matís y los dos Mutis. Orígenes de la anatomía vegetal y de la sinantercología en América. Bogotá: Academia Colombiana de Ciencias Exactas, Físicas y Naturales, 2000.

Dussel, Enrique. "Europa, modernidad y eurocentrismo”. La colonialidad del saber: eurocentrismo y ciencias sociales. Perspectivas latinoamericanas. Comp. Edgardo Lander. Buenos Aires: Consejo Latinoamericano de Ciencias Sociales, 2000.

Langebaek, Carl Henrik. "Introducción". El diablo vestido de negro y los cuna del Darién en el siglo XVIII. Jacobo Walburger y su Breve noticia de la Provincia del Darién, de la ley y costumbres de los Yndios, de la poca esperanza de plantar nuestra fé, y del número de sus naturales, 1748. Ed. Carl Henrik Langebaek. Bogotá: Universidad de los Andes / Banco Popular, Fondo de Promoción de la Cultura, 2006.

Nieto Olarte, Mauricio. Orden natural y orden social. Ciencia y política en el Semanario del Nuevo Reyno de Granada. Bogotá: Universidad de los Andes, 2008.

Nieto Olarte, Mauricio y otros. "El influjo del clima sobre los seres organizados y 
la retórica ilustrada en el Semanario del Nuevo Reyno de Granada". Historia Crítica 30 (2006): 91-114.

Osorio Oliveros, María Eugenia. “La botica neogranadina de la Compañía de Jesús: un laboratorio para explorar prácticas médicas en la provincia de Santafé, primera mitad del siglo XVIII". Historia y Memoria 6 (2013):143-169.

Peralta Agudelo, Jaime Andrés. "De 'delirios ignorantes' a 'cultas reflexiones': la Ilustración europea y la apropiación de los saberes de la periferia colonial". Fronteras de la Historia. Revista de Historia Colonial Latinoamericana 19.1 (2014):72-97.

. “Los cuna y sus saberes médicos. La ‘ciencia' de los ‘bárbaros’ bajo la mirada del mundo ilustrado". Historia Crítica 46 (2012): 44-65.

. "Oficiantes del bienestar humano. Curanderos negros en el Pacífico colonial". Todos somos historia. Tomo 2. Ed. Eduardo Domínguez. Medellín: Canal U, 2010.

Pérez Mejía, Ángela María. "Mutis o la trampa de la Mutisia Clematis". Boletín Cultural y Bibliográfico 34.46 (1997): 29-84.

Pimentel, Juan. Testigos del mundo. Ciencia, literatura y viajes en la Ilustración. Madrid: Marcial Pons, 2003.

Pratt, Mary Louise. Ojos imperiales. Literatura de viajes y transculturación. Bernal: Universidad Nacional de Quilmes, 1997.

Prieto, Andrés. Missionary Scientists. Jesuit Science in Spanish South America, 15701810. Nashville:Vanderbilt University Press, 2011.

Restrepo Forero, Olga. "Naturalistas, saber y sociedad en Colombia”. Historia social de la ciencia en Colombia. Tomo 3. Eds. Luis Carlos Arboleda y otros. Bogotá: Colciencias, 1993.

Rodríguez Cuenca, José V. y Arturo Cifuentes Toro. “Tequinas, mohanes, piaches y jeques. Los chamanes en el mundo prehispánico de Colombia”. http:// www.humanas.unal.edu.co/colantropos/files/7414/7373/3405/Tequinas_Rodriguez.pdf (22/11/2018).

Silva, Renán. Los ilustrados de Nueva Granada, 1760-1808. Genealogía de una comunidad de interpretación. Bogotá: Banco de la República / Fondo Editorial Eafit, 2002. 